\title{
Reconfiguration Technique for Optimization of the Photovoltaic Array Output Power under Partial Shading Conditions
}

\author{
Ahmed M. Mahmoud ${ }^{1 *}$, Salah M. Saafan ${ }^{2}$, Ahmed M. Attalla $^{3}$ and Hamdy Elgohary ${ }^{3}$ \\ 1: MS. Student, Department of Electrical Power and Machines, Faculty of Engineering- Ain Shams \\ University, Cairo, Egypt \\ 2: Dr., Electric and Computer Engineering Department, Higher Technological Institute (HTI), 10th of \\ Ramadan City, Egypt \\ 3: Professor Dr., Department of electrical power and machines, Faculty of Engineering-Ain Shams \\ University, Cairo, Egypt
}

Received April 14, 2018; Accepted May 30, 2018; Published June 5, 2018

\begin{abstract}
A partial shading condition is a case under which the PV array is exposed to many problems such as losses of the output power of the PV array, and the PV array has more than one maximum power point (MPP), which makes it so difficult to track the MPP. This paper presents the effect of different partial shading patterns on PV array characteristics and the effect on the output power of the PV array, and provides a comparative literature review on methods to mitigate these effects and the drawbacks of these methods. It also proposed a new reconfiguration strategy that increases the output power of the PV array by $13.8 \%$ from the total power under shadow condition, and a new technique for enhancing the output power of the PV array by $20 \%$ of the total power under fully illumining conditions by controlling the switch matrix between the photovoltaic array and adaptive batteries bank. This paper gives a solution for the problem of the difficulty of tracking the MPP, because the proposed strategy makes only one MPP. The simulation was carried out by using MATLAB Simulink under different shading patterns.
\end{abstract}

Keywords: Photovoltaic Array; Partial shading; Reconfiguration; MATLAB Simulink; Optimization

\section{Introduction}

The use of photovoltaic (PV) cells for producing electricity has been recently increased due to reduced costs and increased efficiency of the energy conversion. They are widely used in many applications to reduce the effect of $\mathrm{CO}_{2}$ emission. However, two of the problems that still affect the performance and reliability of PV modules are shading and mismatch. Shading occurs, when PV system has been installed in some locations where exposure to shading is inevitable. For example, there is not enough land available to build a PV installation to prevent all types of shading. Shading of PV may also occur in the case of leaves, bird droppings or dirt falling on PV cells as well as surrounding structures (building and trees) and the shadows casting over PV cells. The effect of partial shading will reduce the output power of the PV array, and the mismatch may be occurring because cells with different characteristic performance are combined together in an array. The condition of a mismatch may cause power loss. When the characteristic of cells within the 
PV array differs, individual cells may not operate at the optimal condition. As a result, some shaded cells consume power from the unshaded cells, and the output power of the PV array reduces and the shaded cells overheat. This phenomenon is called hot spot and it may cause damage of the PV cells. Bypass diodes are commonly used in PV arrays to protect against the effect of partial shading and hotspot power dissipation. A bypass diode is connected in parallel but in opposite polarity with the PV cell. Under normal operation, each solar cell will be forward biased and therefore the bypass diode will be reverse biased. Typically, one bypass diode is connected with a string [1]. Since the string has the same current because of the series connection, but the shaded cell is reverse biased to conduct the large current of unshaded cells [2-3]. The activation of bypass diodes causes presence of multiple maximum power peaks that make it difficult to track the maximum power point (MPP). This paper presents a solution for optimization of the maximum output power of the PV array and enhancement of the PV array performance. The remaining of the paper is organized as the following: Section 2 Literature review, Section 3 Modelling of the PV array, Section 4 Research method, Section 5 Simulation and results, and Section 6 Conclusions.

\section{Literature Review}

Some authors discussed a great number of methods to track the global MPP of the PV array under partial shading conditions. Ref [4] covered a comparison between some techniques for tracking of the global MPP.

Ref [5] studied the effect of the interconnection of the array according to the shading pattern. The author made simulation on three interconnections of PV: array seriesparallel connection (SP), total cross tie connection (TCT) and bridge linked connection (BL) at different shading patterns. The author concluded that Series-Parallel (SP) interconnection produces the maximum power as compared to Total-Cross-Tied (TCT) interconnection when shadow is portended to be progress on the last row of horizontal modules, while TCT interconnection produces the maximum power as compared to SP interconnections when shadow is portended to be progress on the left column of vertical modules. The drawback of this technique is that the shading pattern must be known.

In Ref [6], a DC-DC converter controlled by a DC signal of adjustable amplitude was used to track the global MPP.

Ref [7] discussed the optimal layout of PV modules within a PV array giving the maximum output power. Author found that the scheme of parallel connection of all the panels of the system was the best possible configuration.

In Ref [8], a reconfiguration of the shaded modules was made within the fixed PV array by using adaptive bank PV modules and switching matrix. The drawbacks of this technique are the high cost of adaptive bank of PV modules and some of this adaptive bank PV modules may be shaded.

In Ref [9], reconfiguration of the PV array by using the rough set technique (RST) was done. This technique depends on a complex mathematical method for reconfiguration of the PV array.

Ref [10] developed a power optimizer software for executing a power conversion and distributing maximum power point tracking to capture maximum PV array tied to the 
electric grid by taking input parameter data about panel, array, shading obstacles, weather data and using this information to perform plane of array irradiance mapping and using this data to develop annual simulation software for power recovery in array during complete or partial shading. But this system required annual update for data and it didn't work accurately if there are unpredictable reason for shading.

In Ref [11], a basic boost converter with several channels was used and the output of the two channel boosts was combined with an uncoupled reactor. This two-channel boost converter increased the output power and efficiency of the PV array, and reduced the harmonic in the output power. This system was controlled by pulse width modulation (PWM) based PI voltage mode controller. However, this converter has non-linearity and non-stability due to its parameter variation and is suitable for low power application only. If the power increased, the size of reactor and the cost increased.

These literature reviews can be summarized as follows: Some authors used different methods for reconfiguration of photovoltaic array during normal operation condition such as ref. [5, 7-9]. Ref. [5] required the user to predict the shading pattern and use the appropriate system configuration, but still there are power losses that didn't substitute. Ref. [4] didn't consider the reconfiguration due to unpredictable condition such as birds and clouds. Ref. [7] suggested a good method for reconfiguration under different shading conditions and ref. [8] substituted the loss occurring due to partial shading by using adaptive PV array, but didn't take in account that the partial shading occurs in the main and alternative PV arrays due to clouds. Ref. [9] suggested a complex method for reconfiguration of the PV array depending on data entry about the shading pattern. If this parameter changed, the system won't work correctly.

Some authors such as ref. [6] and [11] substituted the loss during partial shading by using a power electronics converter that causes the output power of the photovoltaic array to generate multiple power points and causes losses. Some authors suggested different methods for maximum power point such as ref. [4] and [10].

\section{Modelling of the PV Array Circuit}

\subsection{Electrical Model of PV Module (five parameter model)}

There are three models of the PV cell, i.e., ideal model, single diode model and two diode model. In this paper, a single diode five parameter model is used as illustrated in Fig. 1. This electrical circuit of the PV cell represents the behavior of the real cell. This model is called a single diode five parameter model because it depends on five parameters that are the nominal PV current, diode current, series resistance, parallel resistance and output voltage of the PV array. These parameters can be estimated as shown in the literature [12]. 


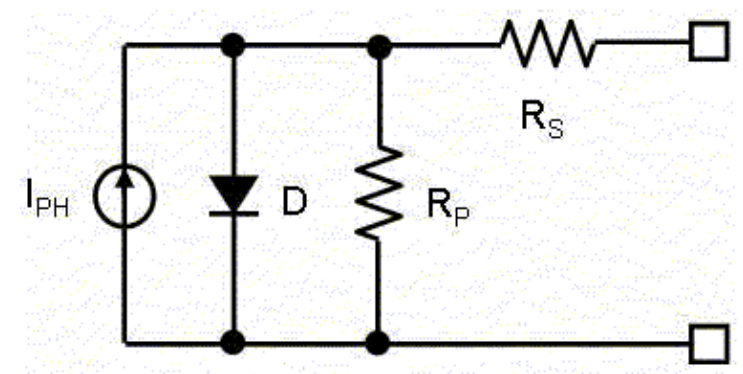

Figure 1. Equivalent circuit of PV cell single diode five parameter model

\subsection{Mathematical Model of PV Module (five parameter model)}

For the circuit shown in Fig. 1 it is possible to obtain Eq. 1:

$$
I=I p H-I D\left(e^{\frac{V}{a v t}}-1\right)-\frac{V+I R s}{R p}
$$

Where IPH is the photovoltaic current, ID is the diode current, V is the PV output voltage, $\mathrm{Vt}$ is the thermal voltage and $\mathrm{Rs}$ is the series resistance. $\mathrm{Rp}$ is the parallel resistance and I is the PV output current. The solution of Eq. 1 gives the I-V characteristic curve of the PV array.

- Thermal voltage

The thermal voltage of a module with Nc cells is given by the Eq. 2 .

$$
V t h=\frac{K T}{q}
$$

Where the $\mathrm{k}$ is the Boltzmann's constant $\left(1.38 \times 10^{-23} \mathrm{~J} / \mathrm{K}\right), \mathrm{q}$ is the electron charge $\left(1.6 \times 10^{-}\right.$ ${ }^{19} \mathrm{C}$ ) and $\mathrm{T}$ is the temperature.

- Diode reverse saturation current (ID)

The diode reverse saturation current can be calculated by substituting the open circuit conditions ( $\mathrm{V}=\mathrm{Voc}, \mathrm{I}=0)$ as shown in Eq. 3.

$$
I D=\frac{I s c}{\exp \left(\frac{V o c}{a N c V t h}\right)-1}
$$

Where Voc is the open circuit voltage, Isc is the short circuit current, a is the ideality factor of the diode and $\mathrm{Nc}$ is the number of cells.

- Photovoltaic current (IPH)

The photovoltaic current IPH depends on the temperature and the solar irradiation as shown in Eq. 4.

$$
I p H=(I p h, \text { reference }+K t(T-T r e f)) \frac{G}{\text { Gref }}
$$

Where Iph, ref is the photovoltaic current at reference irradiance and temperature (1000 $\mathrm{w} / \mathrm{m}^{2}$ and $\left.25^{\circ} \mathrm{C}\right), \mathrm{G}$ is the incident irradiation $\left(\mathrm{w} / \mathrm{m}^{2}\right)$, Tref is the reference temperature at normal condition $\left(25^{\circ} \mathrm{C}\right)$ and Gref is the reference irradiance or nominal irradiance (1000 $\left.\mathrm{w} / \mathrm{m}^{2}\right)$.

\section{Methods and Results}

\subsection{Proposed Reconfiguration Strategy}

The PV array under partial shading conditions has a preferable performance and output power when the shaded modules are located in the same column or in a limited number of columns. Therefore, to obtain optimal optimization of the output power of the 
PV array during shading conditions, it is required to reconfigure the electrical connection of the PV array where the new reconfiguration of the electrical connection of the PV array must make the shaded modules in the same column or in a limited number of columns. The implementation of this task required using of some components (such as a current transformer to measure ( $\mathrm{Ib}$ ) the current passes through a bypass diode and a potential transformer to measure the voltage (v) across the module) and using of electronic switches to make automatic reconfiguration of the modules when the shading occurs. The controller takes order from the current transformer and potential transformer to control the switching of the modules to achieve the best reconfiguration.

The processes of reconfiguration of a $\mathrm{PV}$ matrix $\mathrm{M} \times \mathrm{N}$ where $\mathrm{M}$ is the number of rows and $\mathrm{N}$ is the number of columns are shown in the following flow chart (Fig. 2).

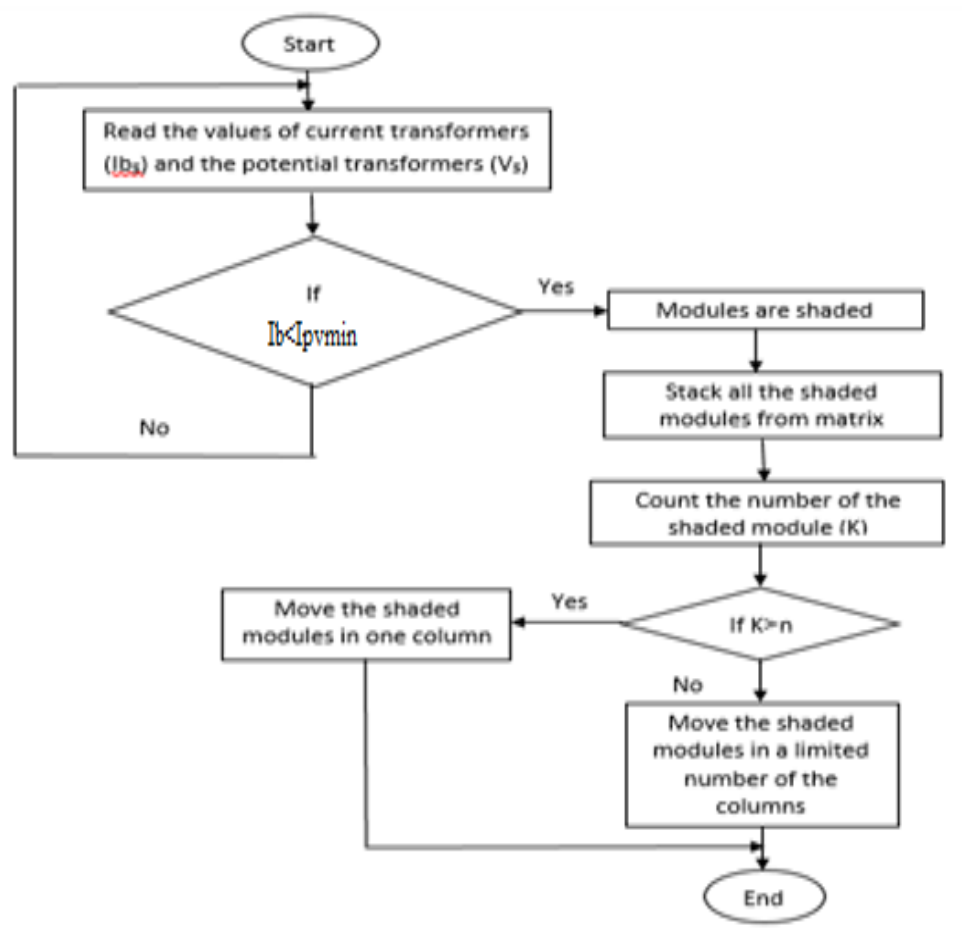

Figure 2. Flow chart of the proposed reconfiguration strategy

\subsection{The Principle of Operation of the Proposed Unit}

The reconfiguration strategy makes optimization of the output power of the PV array during partial shading condition, but the output power of the array is still lower than the output of the PV array under fully illumining condition. Therefore, a new technique as shown in Fig. 3 is used for substituting this loss of the output power of the PV array during partial shading conditions by using a lead acid battery connected in parallel with the PV array. The parameters of the lead acid battery are shown in Table 1 . The voltage of battery is equal to the minimum voltage of series modules under uniform irradiation. When the partial shading occurs, the output current of the photovoltaic array reduced due to partial shading. The current transformer senses the current of the PV array (Ib) and sends the 
signal to the controller. The controller compares the current value sent by the current transformer with the preset value of the current (Ipvm) equal to the minimum value of the PV array current under uniform irradiation. If the current measurement of the current transformers of some modules is lower than Ipvm, then the controller will send commands for electronic switches to stack all shaded modules from the matrix and count all shaded modules. If the number of the shaded modules is equal to the number of the columns, then the controller connects all shaded modules in one column for optimization of the output of the PV array and the battery substitutes these losses due to shadowing. If the number of shaded modules is more than / less than the number of columns, then the controller will connect the shaded modules in less number of columns as shown in m-file shown in Appendix.

Table 1. The parameters of lead acid battery

\begin{tabular}{|l|l|}
\hline Parameter & Value \\
\hline Nominal voltage & $30 \mathrm{~V}$ \\
Rated capacity & $0.4 \mathrm{AH}$ \\
Fully charged voltage & $38.87 \mathrm{~V}$ \\
Nominal discharge current & $0.08 \mathrm{~A}$ \\
Internal resistance & $0.03 \Omega$ \\
\hline
\end{tabular}

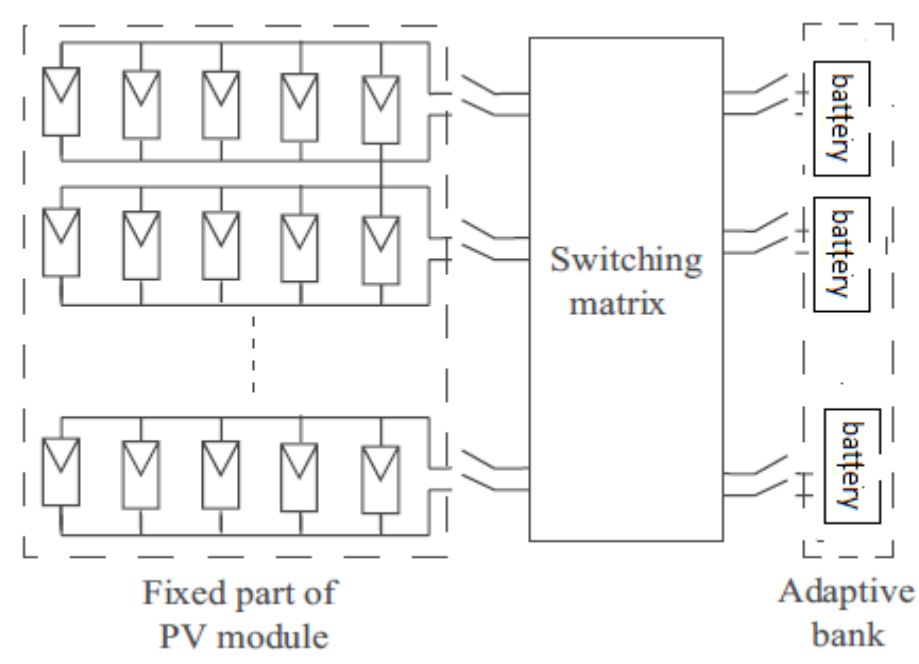

Figure 3. The new proposed unit

\section{The Simulation}

The simulated PV array system of $3 \times 3$ matrix as shown in Fig. 4 . The PV module's parameters were taken from National Renewable Energy Laboratory (NREL)'s System advisor model (January 2014) and sorted in Table 2. 
Table 2. The parameters of the PV module

\begin{tabular}{|l|l|}
\hline Parameter & Value \\
\hline $\mathrm{I}_{\text {MPP }}$ & $8.07 \mathrm{~A}$ \\
$\mathrm{~V}_{\text {MPP }}$ & $10.32 \mathrm{~V}$ \\
$\mathrm{P}_{\mathrm{MPP}}$ & $83.28 \mathrm{~W}$ \\
$\mathrm{I}_{\text {s.c.n. }}$ & $8.62 \mathrm{~A}$ \\
$\mathrm{~V}_{\text {o.c.n. }}$ & $13.30 \mathrm{~V}$ \\
$\mathrm{I}_{0 . n}$ & $1.4176 \mathrm{e}-10 \mathrm{~A}$ \\
$\mathrm{a}$ & 0.99132 \\
$\mathrm{Rs}$ & $0.098 \mathrm{ohms}$ \\
$\mathrm{Rp}$ & $82.11 \mathrm{ohms}$ \\
\hline
\end{tabular}

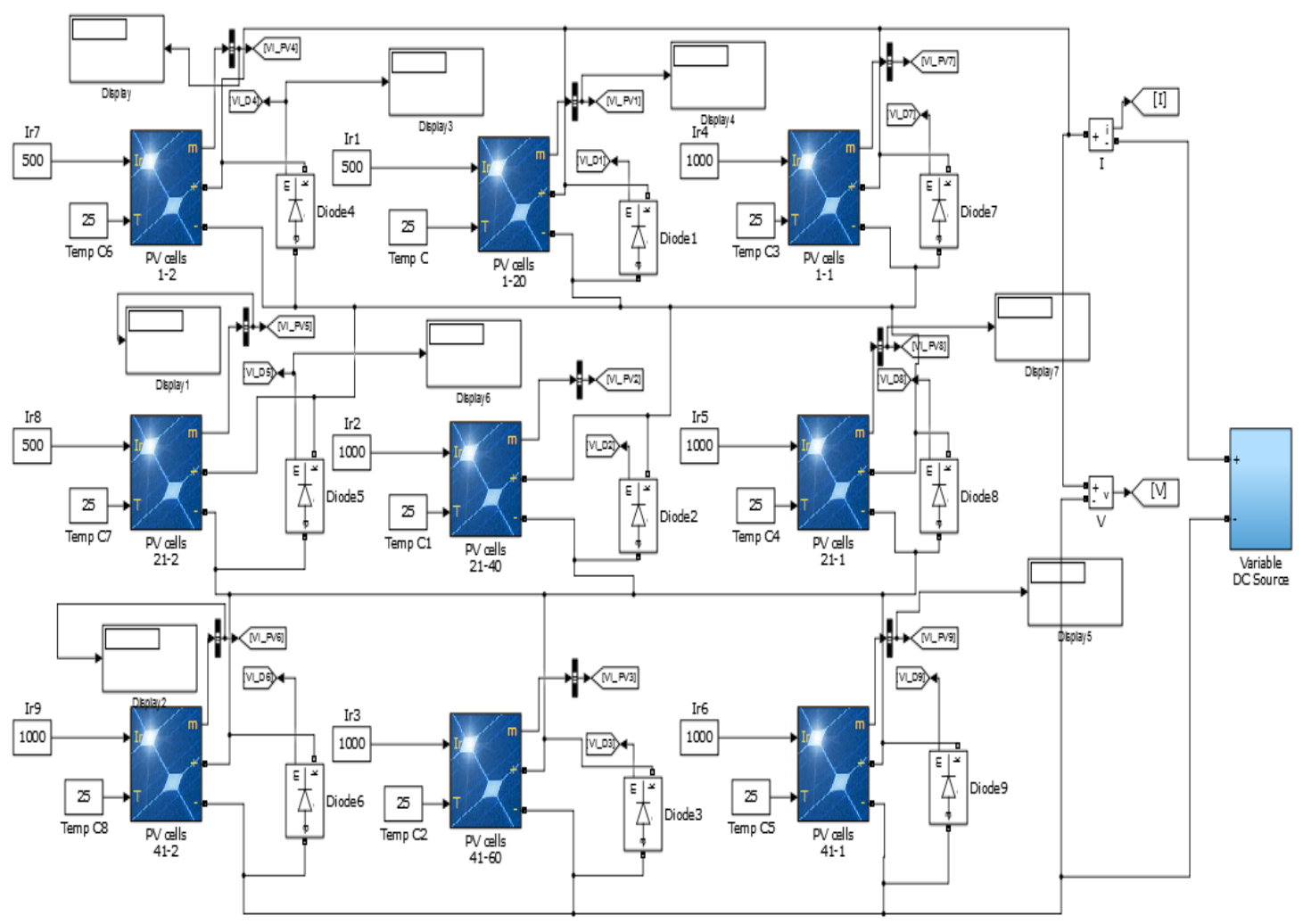

Figure 4. The simulated PV array matrix.

The simulated system was exposed to different irradiance conditions:

\subsection{Uniform Illumination Condition}

The simulated PV array system under uniform illumination condition where all modules are exposed to the same irradiance of $1000 \mathrm{w} / \mathrm{m}^{2}$. Fig. 5(a) shows the I-V and P$\mathrm{V}$ curve characteristics of the simulated system under uniform illumination condition. 


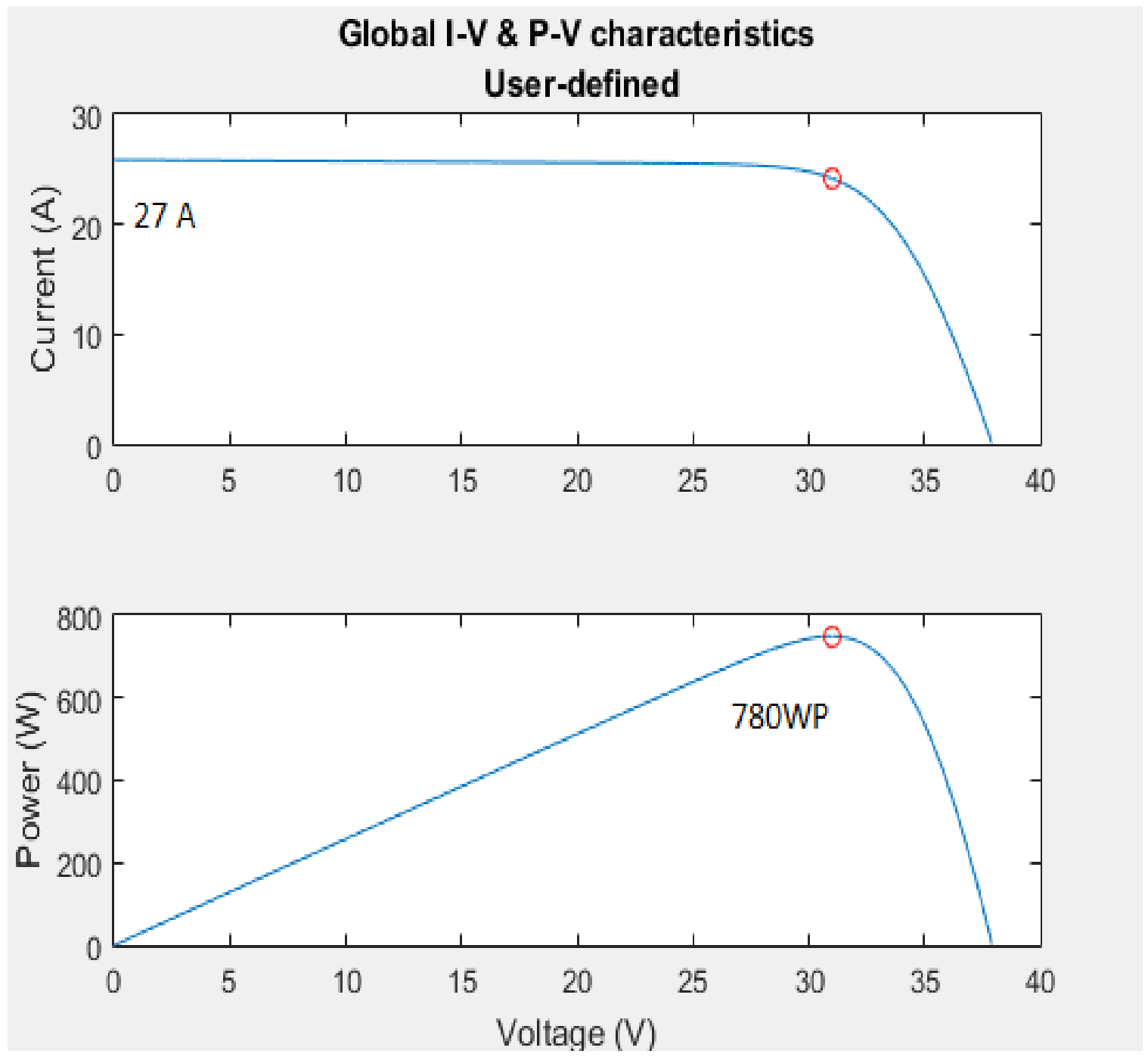

Figure 5 (a). The characteristics of PV matrix under uniform irradiance

\subsection{Partial Shading Condition}

The influence of the shading on the output power of the PV array is discussed with some simulations. The reference pattern is fully illuminated modules that is an array of $3 \times 3$ matrix at irradiance $1000 \mathrm{w} / \mathrm{m}^{2}$ and temperature of $25^{\circ} \mathrm{C}$. This array of 9 modules with its progressive shading is analyzed. Several simulations are carried out considering that the modules from 0 to 9 are shaded. The percentage of the shaded modules to all modules are $33.33 \%$, i.e., three modules are shaded from the matrix. The shading pattern may occur in different manners in the same column or in different columns. The different cases of shading pattern are simulated, and the results are shown in Fig. 5 (b, c, d). 

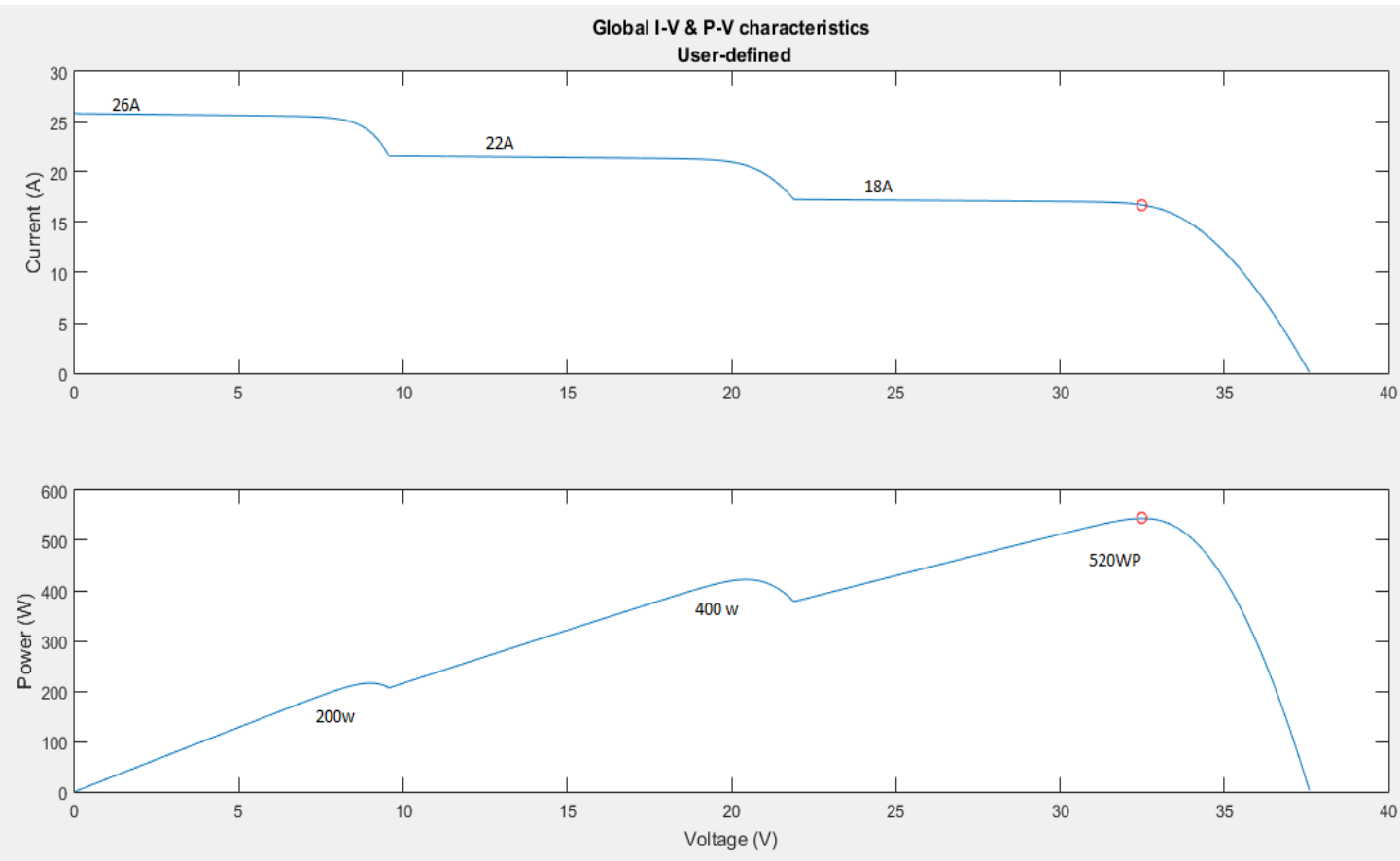

Figure 5 (b). The characteristics of PV matrix under shading pattern in different columns
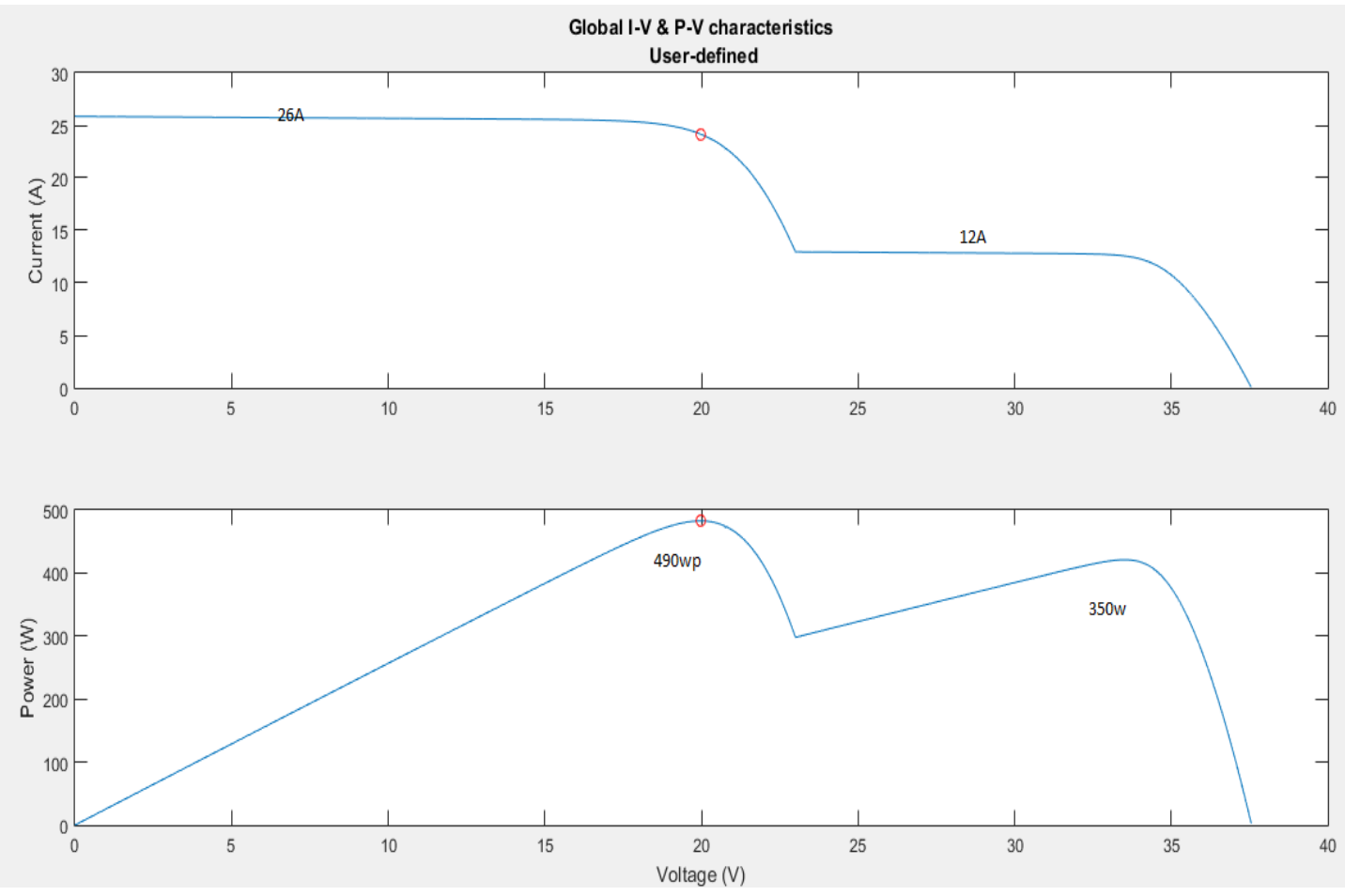

Figure $\mathbf{5}$ (c). The characteristics of PV matrix under shading pattern in the same row 

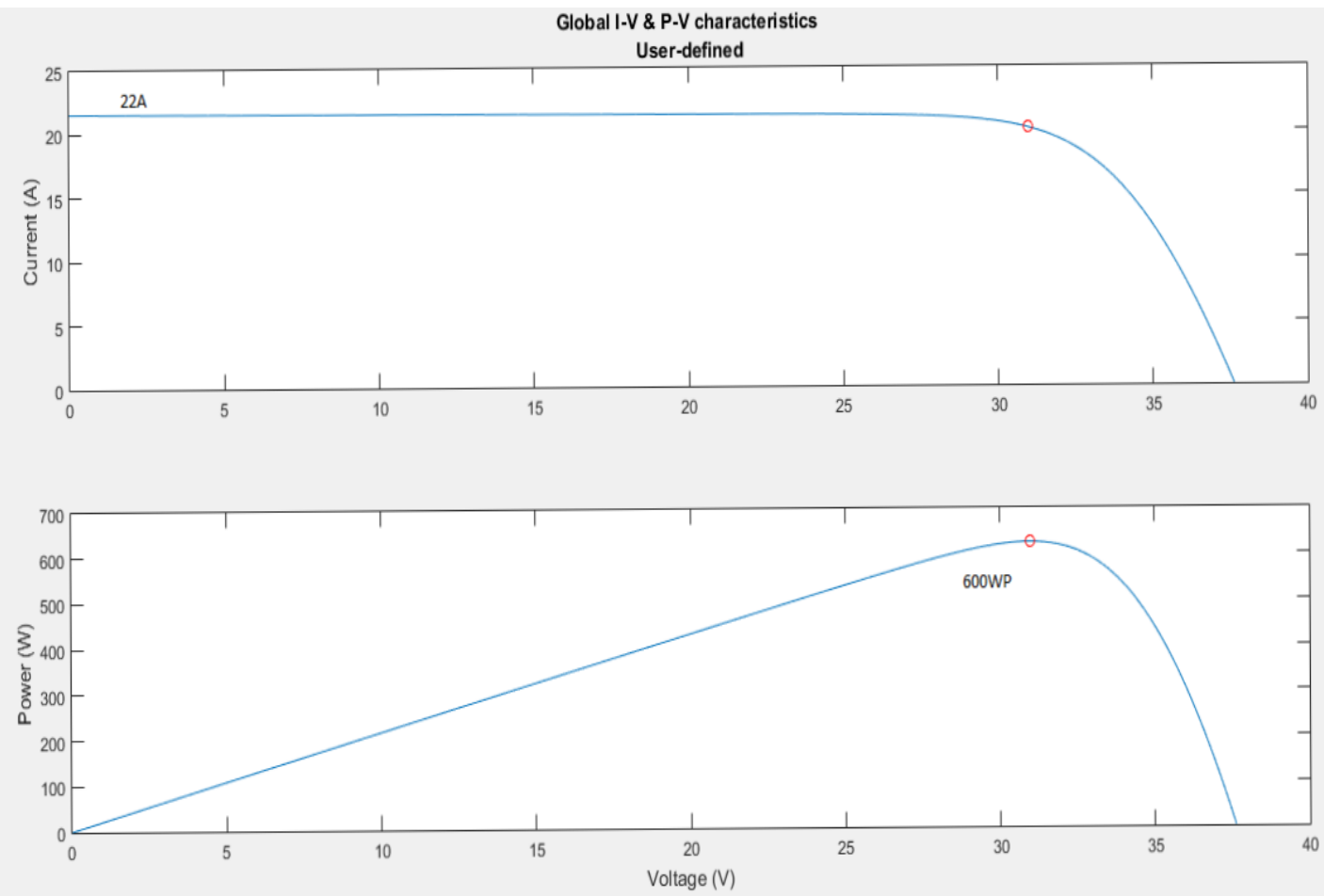

Figure 5 (d). The characteristics of PV matrix under shading pattern in the same column

It's shown from the simulation of the PV matrix under different shading pattern cases that the maximum output power occurred, when all shaded modules in the same columns or in minimum numbers of columns. The maximum power $(600 \mathrm{Wp})$ of the shaded modules in the same column is about $13.8 \%$ higher than the maximum power $(490 \mathrm{Wp})$ of the shaded modules in the same row. Table 3 shows the output power for different reconfiguration at different percentages of shading.

Table 3. The output power for different reconfiguration at different percentage of shading

\begin{tabular}{|l|l|l|l|l|}
\hline $\begin{array}{l}\text { Percentage of } \\
\text { shading }\end{array}$ & $\begin{array}{l}\text { Number of the } \\
\text { shaded modules }\end{array}$ & $\begin{array}{l}\text { Pout (the } \\
\text { shaded modules } \\
\text { in the same } \\
\text { row) }\end{array}$ & $\begin{array}{l}\text { Pout (the } \\
\text { shaded module } \\
\text { in the same } \\
\text { column) }\end{array}$ & $\begin{array}{l}\text { Pout (the } \\
\text { shaded module } \\
\text { in different } \\
\text { columns) }\end{array}$ \\
\hline $10 \%$ & 1 & $700 \mathrm{Wp}$ & $700 \mathrm{Wp}$ & $700 \mathrm{Wp}$ \\
\hline $20 \%$ & 2 & $580 \mathrm{Wp}$ & $650 \mathrm{Wp}$ & $650 \mathrm{Wp}$ \\
\hline $30 \%$ & 3 & $490 \mathrm{Wp}$ & $600 \mathrm{Wp}$ & $520 \mathrm{Wp}$ \\
\hline $40 \%$ & 4 & $400 \mathrm{WP}$ & $500 \mathrm{Wp}$ & $500 \mathrm{Wp}$ \\
\hline $50 \%$ & 5 & $480 \mathrm{Wp}$ & $480 \mathrm{Wp}$ & $480 \mathrm{Wp}$ \\
\hline
\end{tabular}

The simulated system of the proposed unit is shown in Fig. 6(a). The output power of the PV array will increase by $20 \%$ of the total output power during fully illumining by using the new technique as shown in Fig. 6 (b). 


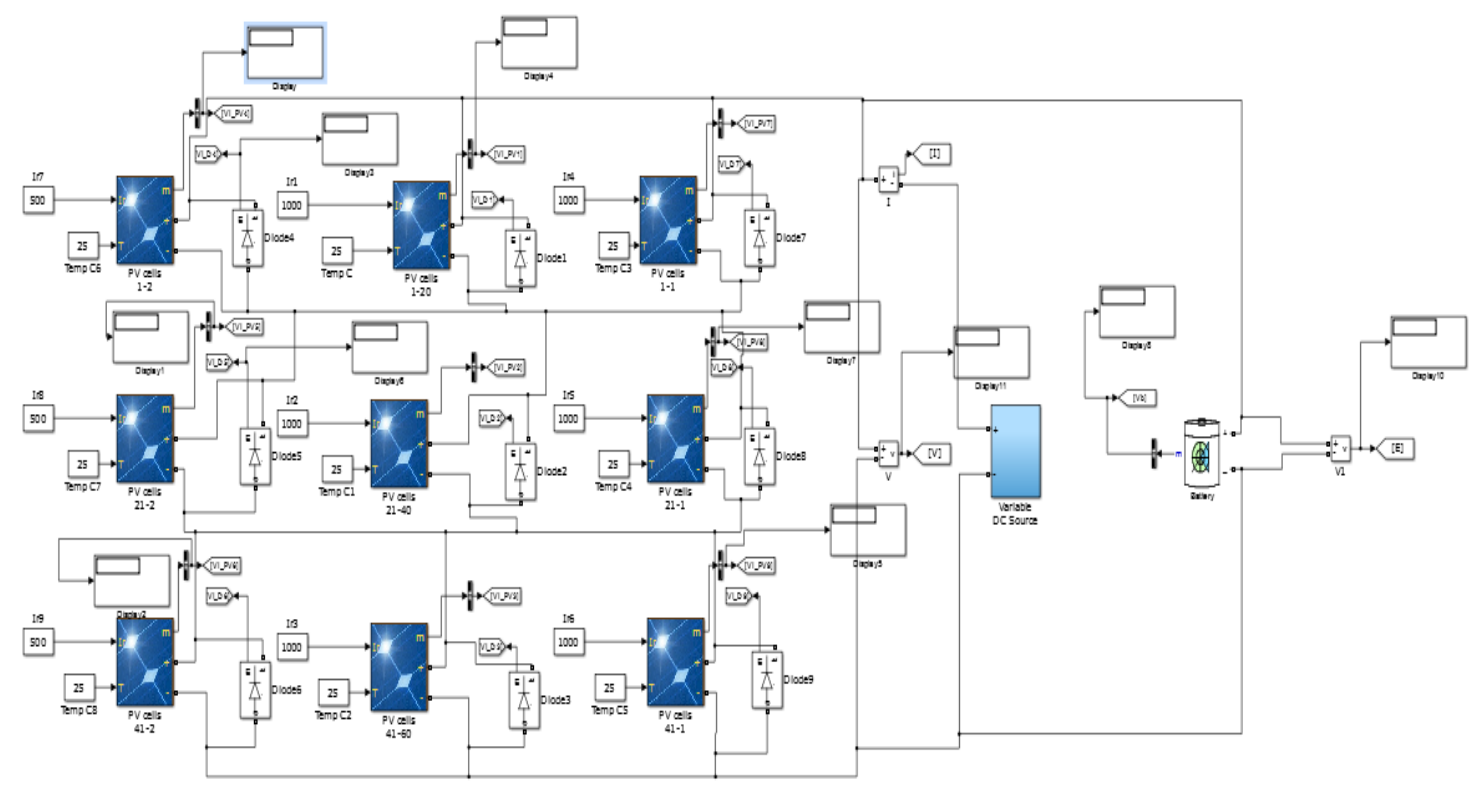

Figure $6(a)$. The proposed unit of PV $3 \times 3$ matrix by using a new technique
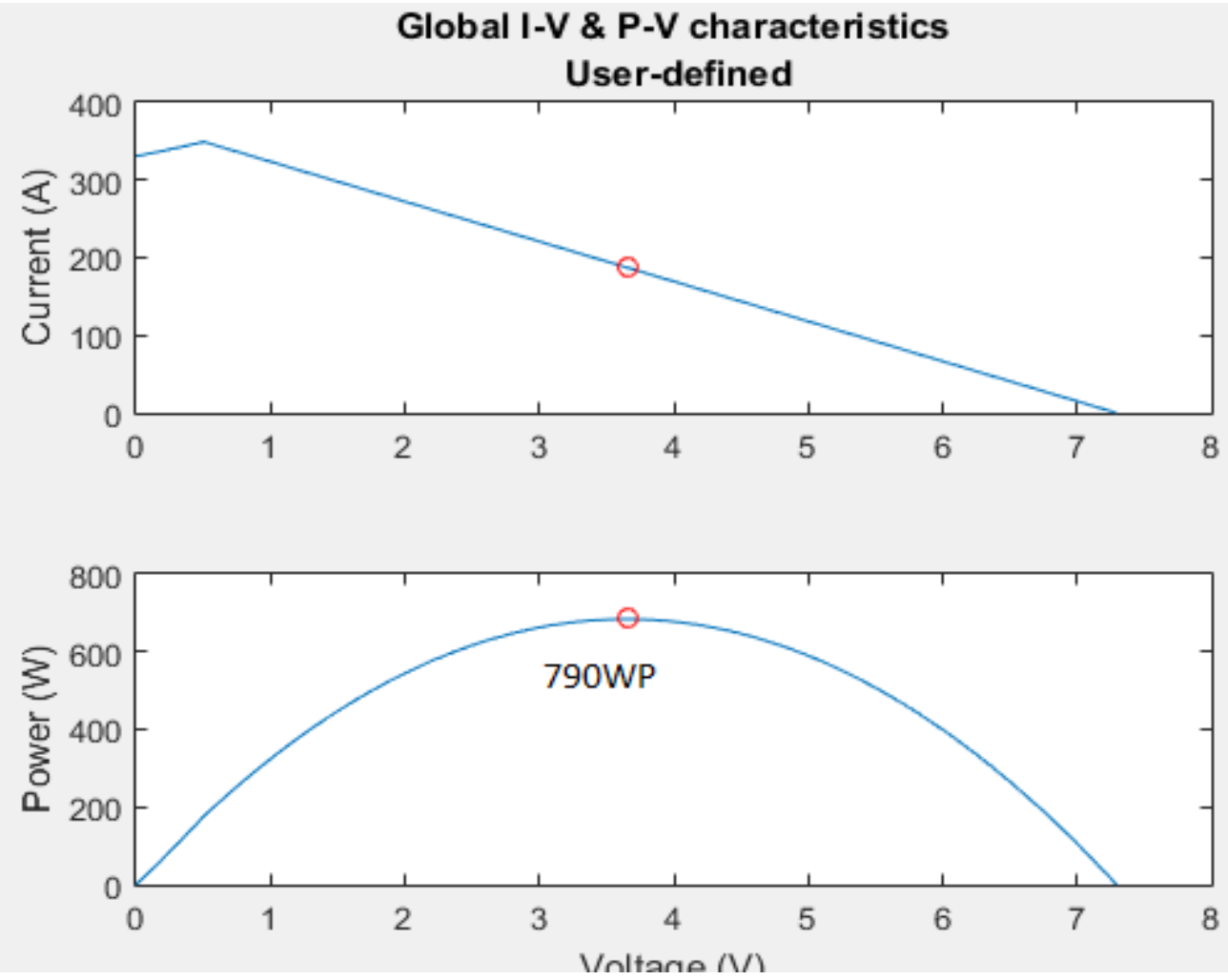

Figure 6 (b). The characteristic of PV $3 \times 3$ matrix by using a new technique 


\subsection{A Comparison of Power Enhancement of the Proposed Method with Different Existing Methods}

There are three existing methods for reconfiguration of the PV array under partial shading conditions. In the literature [8], authors made reconfiguration during the partial shading and substituted the loss of power by using alternative PV modules. But this method isn't an effective approach when the partial shading is due to clouds covering the main and alternative PV modules. The proposed technique in this paper used a storage device (a battery) to substitute the loss that occurs during the partial shading condition and also minimize the loss during partial shading. In the literature [9], authors made reconfiguration by a complex method and didn't substitute the loss of the power. In the literature [13], authors maximized the output power of the PV array by using a battery, but the output of the PV array has multiple power peaks that cause problem for MPPT. In this paper, the output waveform has a unique MPP.

\section{Conclusions}

In this paper, a novel strategy for reconfiguration of the PV array under partial shading conditions is presented. This new strategy increases the output power during the partial shading by $13.8 \%$, prevents producing multiple MPPs, and solves the problems of tracking the MPP during the partial shading. A new technique with using a lead acid battery is presented to increase the output power of the PV under shading condition by $20 \%$, which is similar to the output power of the array under fully illumining condition. The paper simulated the PV array with different shading parameters to optimize the output power during partial shading.

\section{CONFLICTS OF INTEREST}

The authors declare that there is no conflict of interests regarding the publication of this paper.

\section{REFERENCES}

[1] Mäki, A., Valkealahti, S., \& Leppäaho, J. (2012). Operation of series-connected silicon-based photovoltaic modules under partial shading conditions. Progress in photovoltaics: research and applications, 20(3), 298-309.

[2] Spertino, F., \& Akilimali, J. S. (2009). Are Manufacturing I-V Mismatch and Reverse Currents Key Factors in Large Photovoltaic Arrays? IEEE Transactions on Industrial Electronics, 56(11), 4520-4531.

[3] Mastromauro, R. A., Liserre, M., \& Dell'Aquila, A. (2012). Control issues in single-stage photovoltaic systems: MPPT, current and voltage control. IEEE Transactions on Industrial Informatics, 8(2), 241-254. 
[4] Subudhi, B., \& Pradhan, R. (2013). A comparative study on maximum power point tracking techniques for photovoltaic power systems. IEEE Transactions on sustainable energy, 4(1), 89-98.

[5] Pareek, S., \& Dahiya, R. (2014). Output Power Maximization of Partially Shaded 4* 4 PV field by Altering its Topology. Energy Procedia, 54, 116-126.

[6] Koutroulis, E., \& Blaabjerg, F. (2012). A new technique for tracking the global maximum power point of PV arrays operating under partial-shading conditions. IEEE Journal of Photovoltaics, 2(2), 184-190.

[7] Candela, R., Di Dio, V., Sanseverino, E. R., \& Romano, P. (2007, May). Reconfiguration techniques of partial shaded PV systems for the maximization of electrical energy production. In Clean Electrical Power, 2007. ICCEP'07. International Conference on (pp. 716-719). IEEE. DOI: 10.1109/ICCEP.2007.384290

[8] Bidram, A., Davoudi, A., \& Balog, R. S. (2012). Control and circuit techniques to mitigate partial shading effects in photovoltaic arrays. IEEE Journal of Photovoltaics, 2(4), 532-546.

[9] dos Santos, P., Vicente, E. M., \& Ribeiro, E. R. (2011, September). Reconfiguration methodology of shaded photovoltaic panels to maximize the produced energy. In Power Electronics Conference (COBEP), 2011 Brazilian (pp. 700-706). IEEE. DOI: 10.1109/COBEP.2011.6085266

[10] MacAlpine, S. M., Erickson, R. W., \& Brandemuehl, M. J. (2013). Characterization of power optimizer potential to increase energy capture in photovoltaic systems operating under nonuniform conditions. IEEE Transactions on Power Electronics, 28(6), 2936-2945.

[11] Emar, W., Huneiti, Z., \& Hayajneh, S. (2015). Analysis, Synthesis and Simulation of Compact Two-channel Boost Converter for Portable Equipments Operating with a Battery or Solar Cell. Procedia Computer Science, 65, 241-248.

[12] Belhaouas, N., Cheikh, M. A., Malek, A., \& Larbes, C. (2013). Matlab-Simulink of photovoltaic system based on a two-diode model simulator with shaded solar cells. Revue des Energies Renouvelables, 16(1), 65-73.

[13] Aldaoudeyeh, A. M. I. (2016). Photovoltaic-battery scheme to enhance PV array characteristics in partial shading conditions. IET Renewable Power Generation, 10(1), 108-115. 


\section{Appendix}

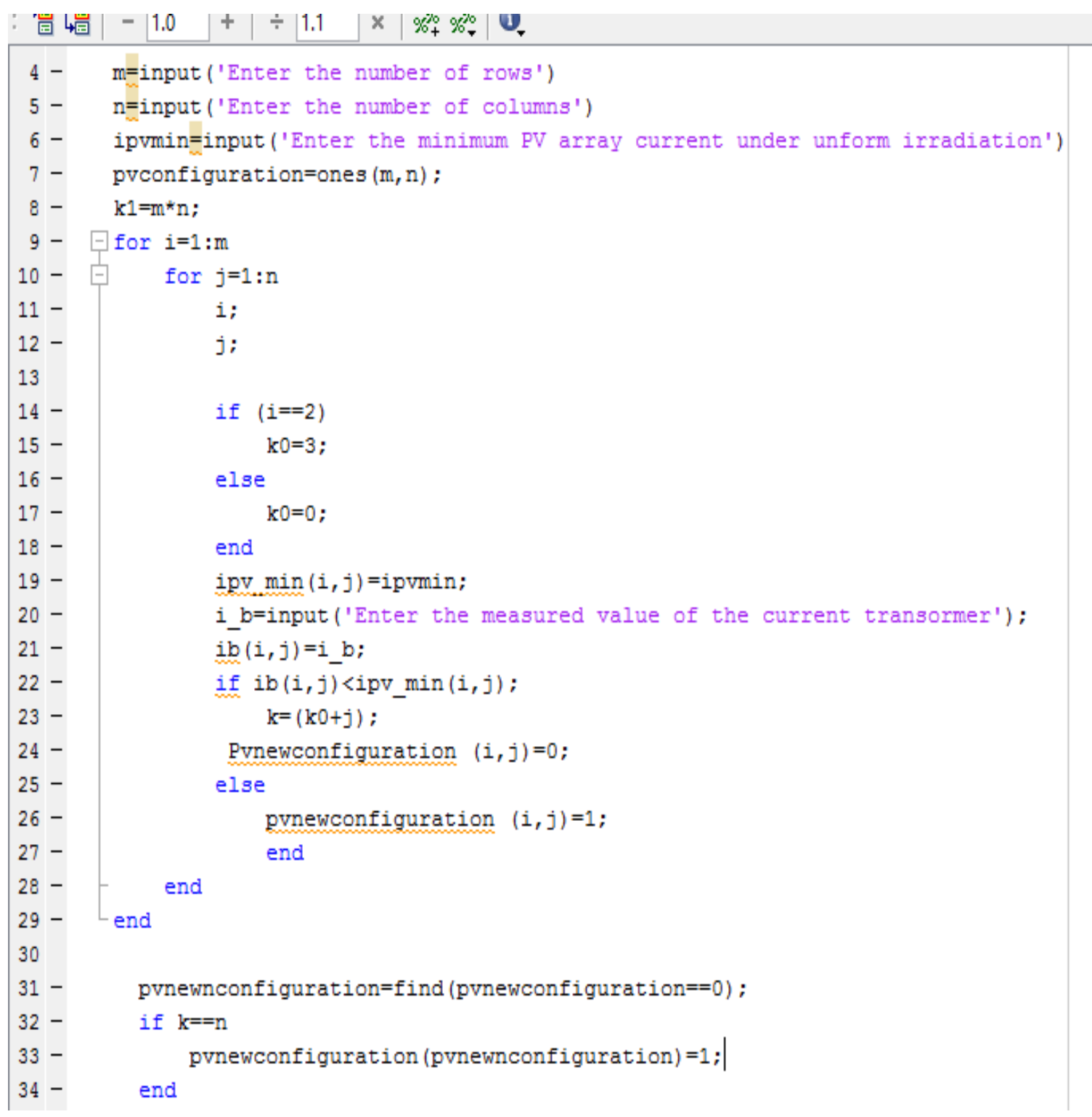

Article copyright: $\mathbb{C} 2018$ Ahmed M. Mahmoud, Salah M. Saafan, Ahmed M. Attalla and Hamdy Elgohary. This is an open access article distributed under the terms of the Creative Commons Attribution 4.0 International License, which permits unrestricted use and distribution provided the original author and source are credited.

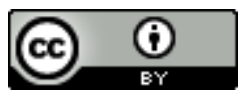

